\title{
Aggressiveness of the Fungi Responsible for Pod Rot in Cropping Systems Based on Cocoa Trees (Theobroma cacao L.) in Cameroon
}

\author{
Ze Medjap Abel Second ${ }^{1, ~ *, ~ Y a o u b a ~ A o u d o u ~}{ }^{1}$, Bikomo Mbonomo Rene ${ }^{2}$ \\ ${ }^{1}$ Department of Plant Protection (FASA), University of Dschang, Dschang, Cameroon \\ ${ }^{2}$ Department of Agriculture and Agropastoral, Higher Normal School of Technical Education of Ebolowa, University of Yaounde I, Yaounde, \\ Cameroon
}

Email address:

abel7032@yahoo.com (Ze M. A. Second), Yaoubaaoudou@yahoo.fr (Y. Aoudou),r_bikomo@yahoo.fr (B. M. René)

${ }^{*}$ Corresponding author

To cite this article:

Ze Medjap Abel Second, Yaouba Aoudou, Bikomo Mbonomo Rene. Aggressiveness of the Fungi Responsible for Pod Rot in Cropping Systems Based on Cocoa Trees (Theobroma cacao L.) in Cameroon. American Journal of Agriculture and Forestry.

Vol. 9, No. 3, 2021, pp. 156-163. doi: 10.11648/j.ajaf.20210903.19

Received: May 14, 2021; Accepted: May 31, 2021; Published: June 7, 2021

\begin{abstract}
To evaluate the Aggressiveness of the fungi responsible for pod rot in cropping systems based on cocoa trees (Theobroma Cacao L.), 3 cropping systems having cocoa trees were characterized: Cocoa trees associated with fruits and forest trees (S1), Cocoa trees associated with plantains and palm oil (S2) and associated cocoa trees with coffee trees (S3). 150 pods were collected per year for isolation and in-situ pathogenicity tests. Three culture media called V6-agar, V8-agar and Potato - Dextrose - Agar (PDA) were made for the in-vitro culture of fungi associated with pods. The test was conducted using a random split split plots arrangement with 9 replicates. As results obtained: of the 8 mushrooms which were isolated from the pods, only 3 are responsible for the burps. It is about Phytophthora megakarya, Botryodiplodia theobromae and Colletotrichum gloeosporioides. Black pods disease caused by P. megakarya was the most aggressively from cocoa pods associated with fruits and forest trees at a decay rate of 5\% during a dryng season and $55 \%$ during a rainy season. The lesion areas developed by $P$. megakarya ranged from $40 \mathrm{~cm}^{2}$ during a dryng season to $220 \mathrm{~cm}^{2}$ during a rainy season. Cropping system having cocoa trees associated with fruits and forest trees (S1) is the most vulnerable to the the Aggressiveness of the fungi responsible for pod rot.
\end{abstract}

Keywords: Aggressiveness, Croping System, Decay Rate, Lesion Area

\section{Introduction}

Cocoa orchards in the equatorial and Sudano-Guinean zone are under strong pressure from diseases and pests [1]. Brown pod rot caused by Phytophthora megakarya is the most common disease causing losses in cocoa production of up to $100 \%$ if no phytosanitary control measures are considered [2]. However, other diseases such as black pod rot, anthracnose, black rot and witches' broom are on the rise and present with various symptoms leading to pod loss which can range from 25 to $30 \%$ [3].

Numerous trials have already been conducted to assess the mechanisms of action of cocoa pests and control strategies to control the expansion of these microorganisms in cocoa trees.
However, very little work focused on the climatic and environmental factors that drive variability in the level of aggressiveness of the fungi responsible for rotting cocoa pods. The present study therefore proposes to assess the influence of cocoa-based cropping systems and the seasons of the year on the aggressiveness of the fungi responsible for rots.

\section{Materials and Methods}

\subsection{Location of the Study Area}

The study was carried out in three localities located in 
three different agroecological zones of Cameroon, in particular:

1. Akonolinga, located in the Center region of Cameroon, at $3^{\circ} 46^{\prime} 57.95^{\prime}$ ' $\mathrm{N}$ latitude and $12^{\circ} 14^{\prime}$ $56.65^{\prime}$ E longitude. The prevailing climate is equatorial of the Guinean type with bimodal rainfall characterized by two dry seasons alternating with two rainy seasons;

2. Dizangué, located in the Littoral region, between $9^{\circ} 41$ and $9^{\circ} 50$ East longitude and between $4^{\circ} 42$ and $4^{\circ} 53$ North latitude. The climate is of Cameroonian equatorial type characterized by two seasons: an intensive rainy season from March to October and a dry season from November to February;

3. Tonga, located in the western highlands region of Cameroon, at $4^{\circ} 58^{\prime \prime} 11.13 " \mathrm{~N}$ latitude and $10^{\circ} 42$ "04.80 E longitude. The climate of this Sudano-Guinean-type locality particularly dominated by a long rainy season from March to November and a dry season of 2 to 4 months.

\subsection{Equipment}

\subsubsection{Characterization of Plots}

The characterization of the plots was carried out according to several criteria, in particular: the geographical coordinates of the plot, the age of the stems, the cultural association, the variety of cocoa tree, the origin of the seed, the area of the plot and the type shading. This characterization made it possible to validate with the 3 cocoa-based cropping systems, in particular: the cocoa system associated with fruit trees and forest species, the cocoa system associated with bananas and oil palms and the cocoa system associated with coffee trees. 9 plots were chosen at random from each system and in each plot two plots of $1000 \mathrm{~m} 2$ each were measured.

\subsubsection{Sources of Climate Data}

The relative humidity as well as the maximum and minimum temperatures were measured in the experimental plots directly above the cocoa trees every day during the dry season (from January to March) and during the dry season (from August to October). over a period of 3 years (from 2017 to 2019).

\subsubsection{Plant Material}

The healthy pods were used to carry out the pathogenicity tests (in-vitro and in-situ) of the fungi. Rotten pods have been used for the isolation and identification of fungi responsible for pod rot.

\subsubsection{Laboratory Equipment}

V6 - agar, V8 - Agar and Potato - Dextrose - Agar (PDA) culture media were used as substrates for the isolation and growth of cocoa pod fungi.

\subsection{Methods}

\subsubsection{Collection of Pod Samples}

150 pods were collected separately from the village plantations of the 3 cropping systems characterized. These pods were stored in plastic bags bearing the collection coordinates for the isolation of fungi associated with cocoa pods.

\subsubsection{Preparation of Culture Media}

The culture media were made from vegetables chosen according to the quantities recommended for each type of media. These vegetables were weighed and crushed in 100 $\mathrm{ml}$ of distilled water using a Moulinex. Subsequently $150 \mathrm{ml}$ of juice of macedonia, $20 \mathrm{~g}$ of Agar and $3 \mathrm{~g}$ of $\mathrm{CaCO}_{3}$ were added to it and $1 \mathrm{ml}$ of vegetable oil (Olio) to promote sporulation [4]. The collected filtrate was seasoned with $20 \mathrm{~g}$ of Agar, $40 \mathrm{~g}$ of Dextrose (PDA medium) and $1 \mathrm{~g}$ of Chloramphenicol (to prevent the growth of bacteria). The volume of the medium was made up to $1000 \mathrm{ml}$ with distilled water [5].

\subsubsection{Isolation, Purification and Identification of Fungi Associated with Cocoa Pods}

The pod surface was pre-washed with tap water, then subjected to a series of disinfections with $95 \%$ ethanol for 30 seconds, in $10 \%$ sodium hypochlorite, for 2 minutes. The pods were then rinsed three times with sterile distilled water to remove traces of disinfectant $[6,7]$. Using a sterile scalpel. The fragments from the growth front of the lesion were taken and cultured on selective medium contained in $90 \mathrm{~mm}$ diameter Petri dishes. The identification of the isolated fungal species was made on the basis of the morphological characters of the mycelium (septate or non-septate) and fruiting bodies (conidia) observed under an ordinary microscope.

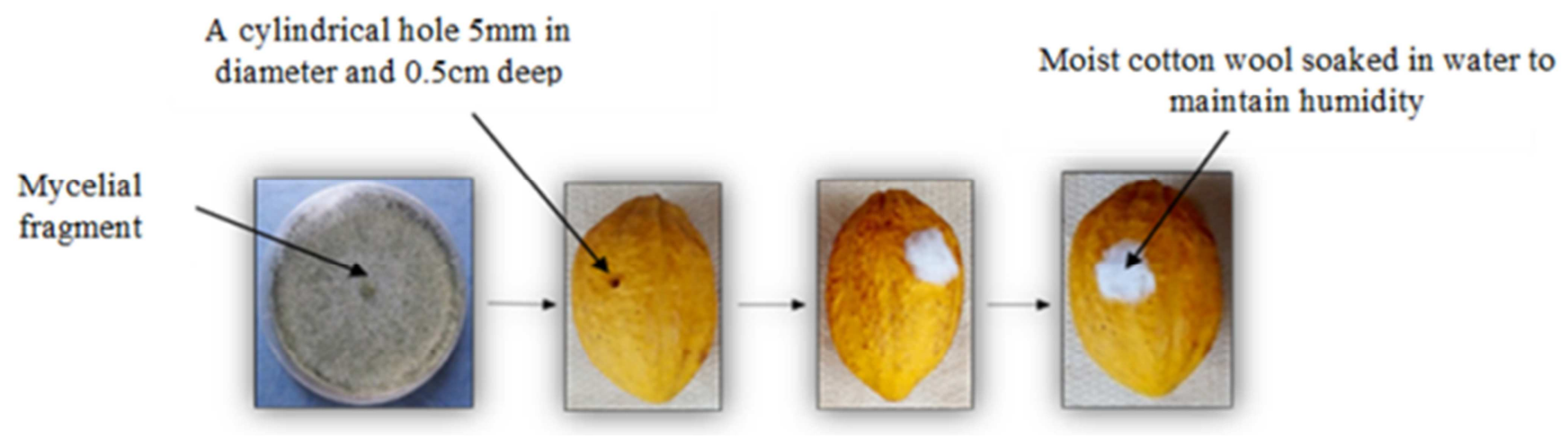

Figure 1. Different stages of inoculation of healthy pods with sporangia of mycelial explants of isolated and identified fungi. 


\subsubsection{Pathogenicity Test of Isolated Fungal Strains for the Identification of Pods Responsible for Pod Rots}

Healthy pods of approximately the same age (identical morphology, size and mass) were washed with tap water and soaked in 3\% sodium hypochlorite solution for 3 minutes. They were then subjected to three successive rinses of 15,10 , and 5 minutes with sterilized distilled water, and dried on blotting paper. A cylindrical hole $5 \mathrm{~mm}$ in diameter and $0.5 \mathrm{~cm}$ deep was created in the middle of each pod using a flambé cookie cutter. A $5 \mathrm{~mm}$ diameter mycelial fragment from each isolated fungus was inserted into each pod, then covered with moist cotton wool soaked in water to maintain humidity. (Figure 1).

\subsubsection{Experimental Devices}

The study was carried out using a split plot device with 9 repetitions. The studied parameters were observed on a total of 54 samples.

\subsection{Variables Measured}

Frequency of fungi isolated and identified from rotten pods. The frequency of isolation of each fungal species was calculated by the following formula:

$$
\mathrm{F}(\%)=\frac{\mathrm{NAFS}}{\mathrm{TNAAFS}} \times 100
$$

NAFS: Number of appearances of a fungal species; TNAAFS: Total number of appearances of all fungal species

\subsubsection{Pod Rot Rate}

The rate of rot (MI) caused by each fungal species tested on pods in-situ consisted of a count of all pods that exhibited at least one specific decay symptom. The count of healthy pods and rotten pods the first day of observation corresponded to the appearance of a lesion characteristic of the type of rot observed. The incidence of each type of decay was calculated using the following formula:

$$
\mathrm{ID}(\%)=\frac{\mathrm{NICT}}{\mathrm{TNCTO}} \times 100
$$

I D (\%): Incidence of the disease;

NICT: Number of infected cocoa trees and

TNCTO: Total number of cocoa trees observed

\subsubsection{Surface of Lesions Developed on Pods}

Each inoculated pod was placed in a sterile polyethylene bag and then incubated at $22 \pm 2{ }^{\circ} \mathrm{C}$. Three pods (repetition) were considered per plot. The length (L) and width (W) of lesion growth $(\mathrm{cm})$ were measured every second day after inoculation (DAI) using a flexible and transparent graduated ruler. The lesion developed on the infected pods having an elliptical shape, its area (S) was calculated according to the following formula of [8]:

$$
S=\frac{\pi \cdot \text { L. l }}{4}
$$

Figure 2 below shows the measurement of length and width on a pod showing brown rot lesions.

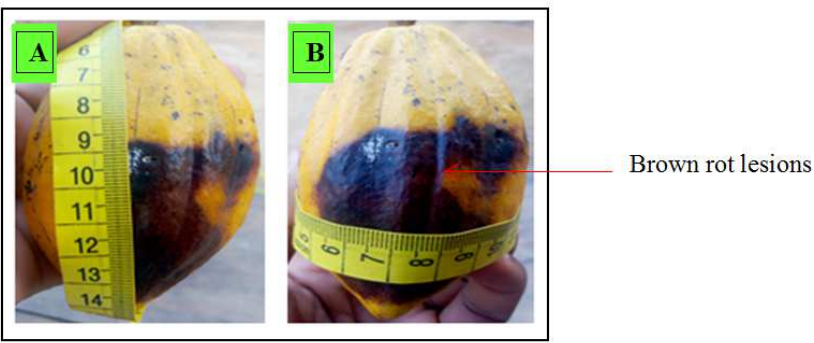

A: Measurement of the length of the lesion L (in $\mathrm{cm}$ )

B: Measurement of the width of the lesion 1 (in $\mathrm{cm}$ )

Figure 2. Measurements of lesion length and width.

\subsection{Data Processing and Statistical Analysis}

The graphics were produced with the Excel spreadsheet. Primary data were subjected to analysis of variance (ANOVA). The calculated mean values of the variables were subjected to the T-multiple comparison test $(\mathrm{p} \leq 0.0001)$.

\section{Results and Discussion}

\subsection{Results}

\subsubsection{Prevalence of Fungi Responsible for Cocoa Bean Rots}

Overall, 8 fungal species were identified as being consistently associated with pods in fields. The frequencies of occurrence of these fungi have varied depending on the cocoa growing systems and the seasons of the year. The diagram in Figure 3 shows the frequency of isolation of each fungus based on cropping systems and seasons of the year. Analysis of this frequency diagram of fungi shows that:

In plots of the cocoa system associated with fruit trees and forest species, Phytophthora megakarya was isolated at the frequent average of $39 \%$, while Botryodiplodia theobromae and Colletotrichum gloeosporioides were isolated with frequencies of 24 and $18 \%$ respectively.

In plots populated with cocoa trees, fruit trees and forest species, Colletotrichum gloeosporioides was isolated at the frequent mean of $39 \%$.

In plots populated with cocoa and coffee, Botryodiplodia theobromae was isolated at the frequent mean of $24 \%$.

In plots populated with cocoa trees associated with banana and oil palms, Fusarium oxysporum was isolated at the frequent average of $27 \%$. 


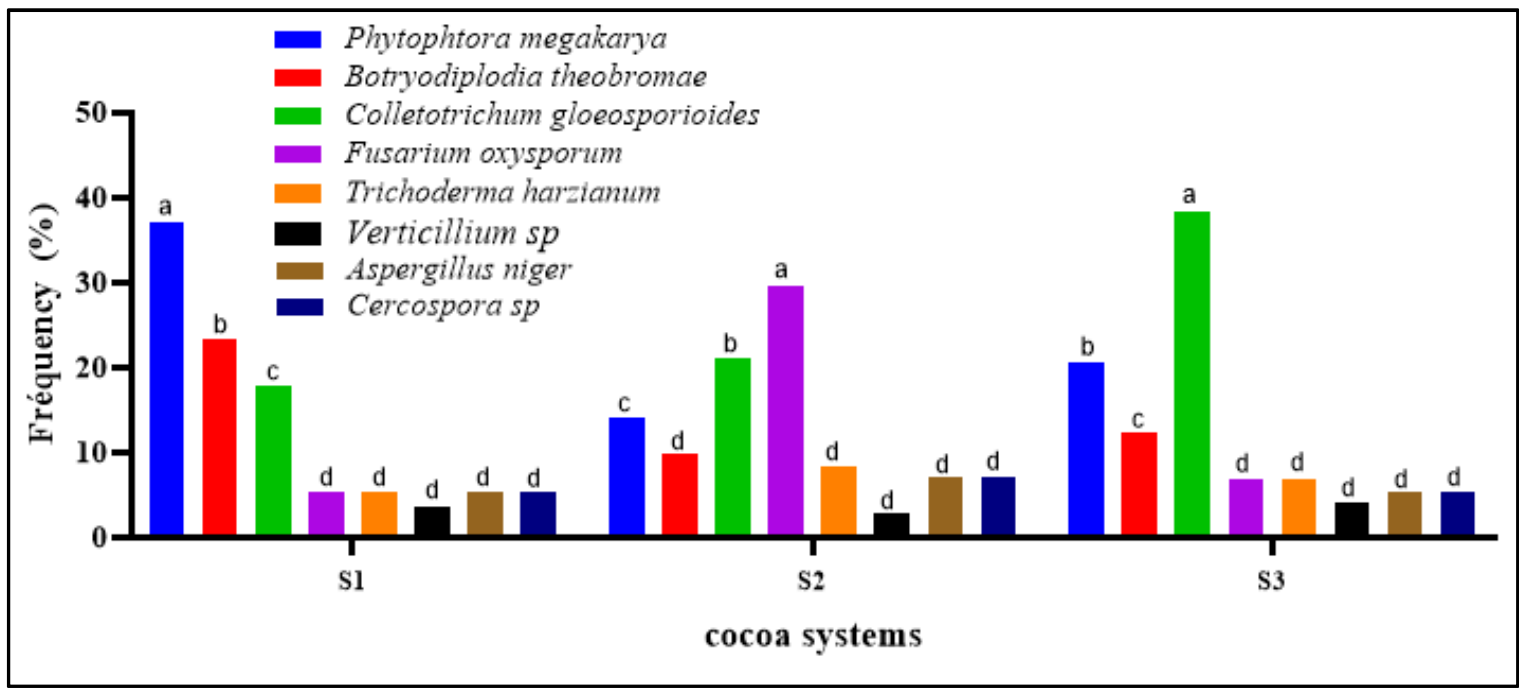

The means assigned the same letter in superscript are not significantly different according to the T-multiple test at $\mathrm{P}<0.0001$.

Figure 3. Frequency diagram of the different fungi identified according to the typologies of cocoa trees.

Legend:

Factors 1: cocoa cropping systems

S1: Cocoa system under shade of fruit trees and forest species

S2: Cocoa system associated with coffee trees

S3: Cocoa system associated with banana and oil palm trees

Factor 2: the seasons of the year

SS: Dry season

\section{SP: Rainy season}

Comparison of the means and standard deviations of the frequencies by the T-multiple comparison test (Table 1) revealed that there is a very highly significant difference $(\mathrm{P}$ $<0.001$ ) between the $P$. megakarya isolation frequencies and the frequencies. Isolation of $B$. theobromae and $C$. gloeosporiodes according to the seasons of the year, the level of relative humidity and the typology of cocoa trees.

Table 1. Comparison of the means and standard deviations of the frequencies of fungi by the T-multiple test according to the effect of the seasons of the year, relative humidity and type of association of crops.

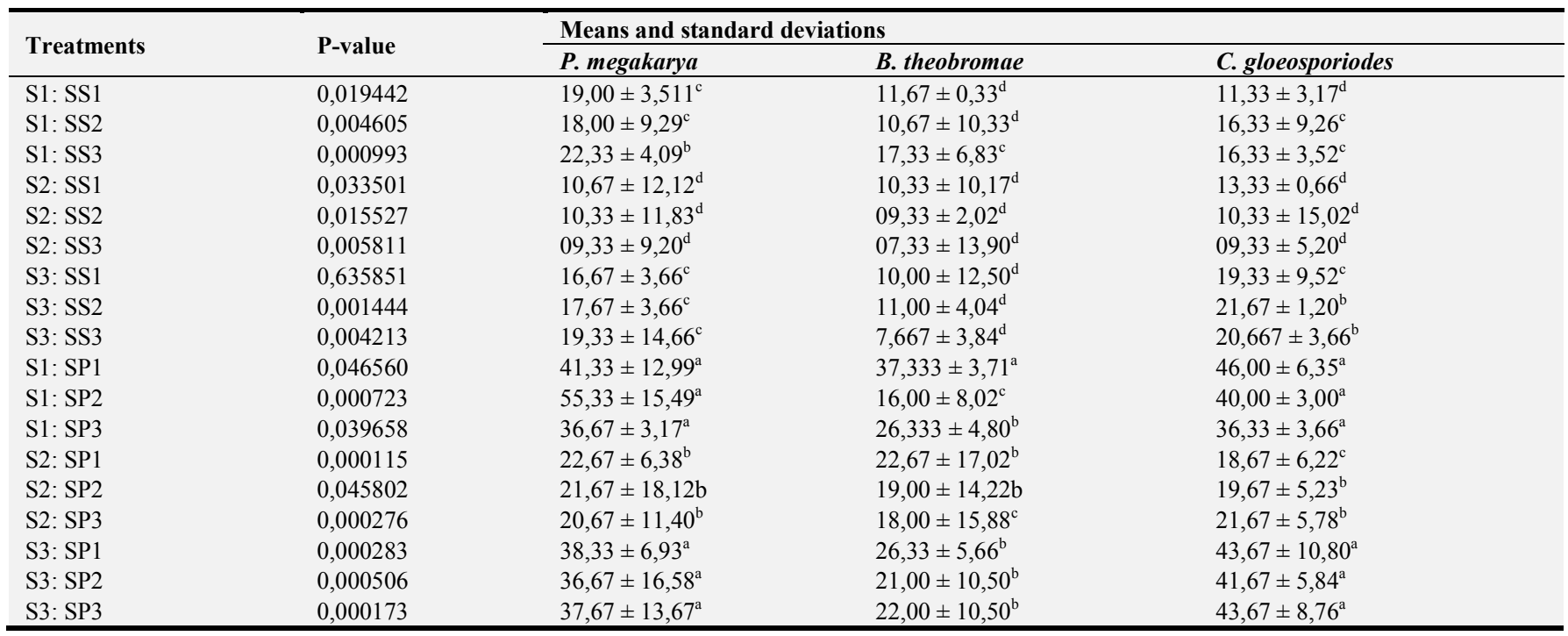

*Means assigned the same letter in the same column are not significantly different according to the T-multiple test at $\mathrm{P} \leq 0.001$

\subsubsection{Pod Rot Rate in Fields}

The rates of the various rots in percentages of affected pods were obtained from the pathogenicity test on healthy pods invitro and in-situ. Of the 8 fungi that were isolated from the rotten pods, only 3 including: P. megakarya, B. theobromae and $C$. gloeosporioides caused different rots based on the primary lesions and symptoms observed over time.
Microscopic observation of pure cultures of these different fungi, 12 days old, revealed that: Phytophthora megakarya is characterized by the whitish color of its colony and its filamentous texture. Botryodiplodia theobromae exhibited a yellow fibrous mycelium. Colletothrichum gloeosporioides showed a whitish cottony mycelium. Fusarium oxysporum showed a somewhat purplish appearance. 


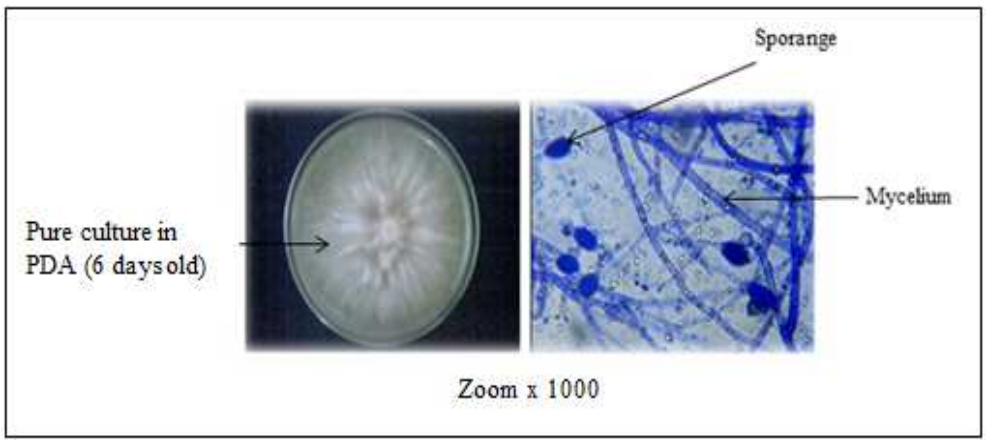

Figure 4. Morphology of Phytophthora megakarya.

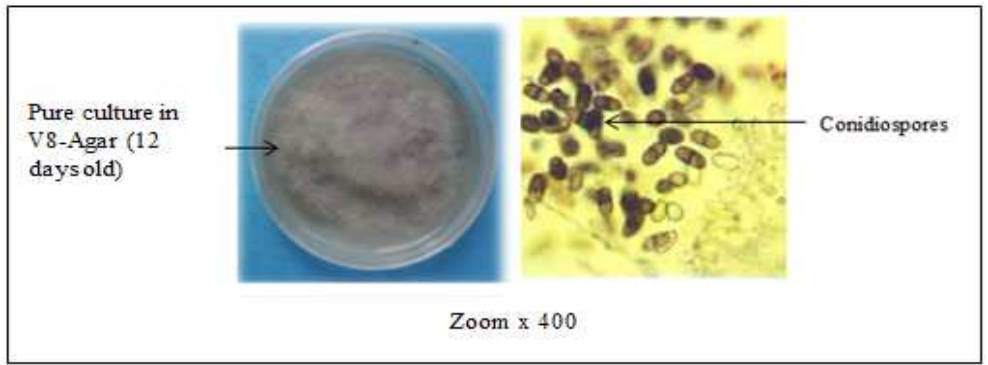

Figure 5. Morphology of Botryodiplodia theobromae.

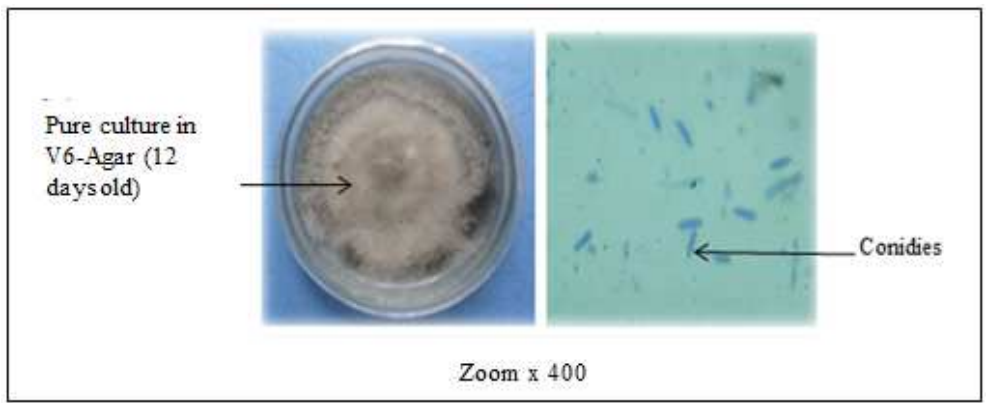

Figure 6. Morphology of Colletotrichum gloeosporioides.

In plots of the cocoa system under the shade of fruit trees and forest species, brown rot showed higher rates during the rainy season over a period of 3 years. These rates varied from $26 \%$ in $2017,39 \%$ in 2018 and $52 \%$ in 2019. As for black pod rot, it evolved in the same direction, but then with relatively lower rates than those of brown rot.

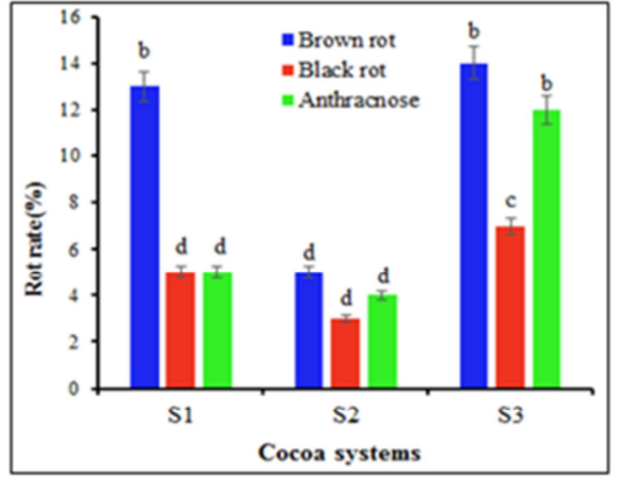

Dry season
In the plots of the cocoa system associated with bananas and oil palms, it was observed that the 03 types of rots presented very low infection rates $(<6 \%)$ in the dry season compared to the rates measured during the growing season. rains whose peak oscillates around $20 \%$.

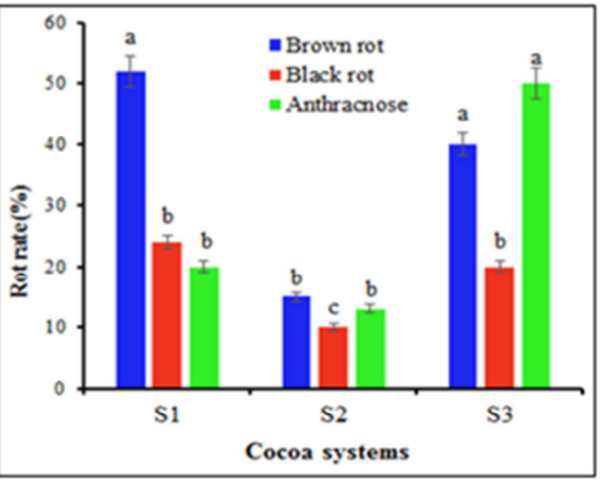

Rainy season

Figure 7. Evolution of pod rot rates in cocoa growing systems according to cocoa growing systems and seasons of the year. 
In plots of the cocoa system associated with coffee trees, brown rot, black rot and anthracnose had such low rates $(<15 \%)$ compared to the rates measured during the rainy season, the evolution of which was noticed. in particular for brown rot, starting from $22 \%$ in 2017 to $39 \%$ in 2019 ; for anthracnose from $28 \%$ in 2017 to $47 \%$ in 2019 .

Caption:

S1: Cocoa system associated with fruit trees and forest species
S2: Cocoa system associated with bananas and oil palms S3: Cocoa system associated with coffee trees

Comparison of the means and standard deviations of pod rot rates by the T-multiple test (Table 2) showed that brown rot had a higher rate $(78.4 \%)$. It was observed during the rainy season under a relative humidity of between 80 and $100 \%$ in the plots of the cocoa system under the shade of fruit trees and forest species.

Table 2. Comparison of means and standard deviations of pod rot rates by the T-multiple test according to the effect of cropping systems and seasons of the year.

\begin{tabular}{|c|c|c|c|c|}
\hline \multirow{2}{*}{ Treatments } & \multirow{2}{*}{ P-value } & \multicolumn{3}{|c|}{ Means and standard deviations } \\
\hline & & Brown rot & Black rot & Anthracnose \\
\hline S1: SS1 & 0,3828 & $09,50 \pm 3,25^{\mathrm{c}}$ & $08,30 \pm 0,31^{\mathrm{c}}$ & $06 \pm 7,63^{\mathrm{c}}$ \\
\hline $\mathrm{S} 1: \mathrm{SS} 2$ & 0,8506 & $09,00 \pm 4^{c}$ & $08,27 \pm 4,87^{\mathrm{c}}$ & $07 \pm 1,15^{\mathrm{c}}$ \\
\hline S1: SS3 & $<0,0001$ & $08,0 \pm 0,57^{\mathrm{c}}$ & $09,00 \pm 0,00^{\mathrm{c}}$ & $07,33 \pm 1,33^{\mathrm{c}}$ \\
\hline $\mathrm{S} 2: \mathrm{SS} 1$ & 0,4566 & $03 \pm 4,80^{c}$ & $03,33 \pm 3,71^{\mathrm{d}}$ & $02,66 \pm 10,66^{\mathrm{d}}$ \\
\hline $\mathrm{S} 2: \mathrm{SS} 2$ & 0,4952 & $03,3 \pm 0,88^{\mathrm{d}}$ & $02,00 \pm 4,35^{\mathrm{d}}$ & $02,66 \pm 11,78^{\mathrm{d}}$ \\
\hline S2: SS3 & 0,5883 & $02,0 \pm 0,57^{\mathrm{d}}$ & $03,23 \pm 6,38^{d}$ & $02,66 \pm 9,24^{\mathrm{d}}$ \\
\hline S3: SS2 & $<0,0001$ & $05,7 \pm 6,35^{\mathrm{c}}$ & $05,53 \pm 4,22^{\mathrm{c}}$ & $0,4 \pm 0,26^{\mathrm{d}}$ \\
\hline S3: SS3 & $<0,0001$ & $05,3 \pm 13,22^{\mathrm{c}}$ & $05,33 \pm 3,33^{\mathrm{d}}$ & $05,33 \pm 3,33^{\mathrm{c}}$ \\
\hline S1: SP1 & 0,0781 & $45,3 \pm 15,30 b$ & $38,00 \pm 4,16 b$ & $34,66 \pm 8,76^{\mathrm{a}}$ \\
\hline $\mathrm{S} 1: \mathrm{SP} 2$ & 0,4186 & $43,0 \pm 15,30^{\mathrm{a}}$ & $23,3 \pm 5,54^{b}$ & $34,33 \pm 8,68^{\mathrm{a}}$ \\
\hline S1: SP3 & 0,9533 & $26,3 \pm 4,63^{\mathrm{b}}$ & $27,0 \pm 9,64 c$ & $25 \pm 2,09^{b}$ \\
\hline S2: SP1 & 0,0344 & $15,7 \pm 6,38 b$ & $12,3 \pm 0,88 b$ & $17,07 \pm 5,34^{\mathrm{b}}$ \\
\hline S2: SP2 & 0,7548 & $27,0 \pm 13,52^{b}$ & $22,0 \pm 6,35^{\mathrm{b}}$ & $12,33 \pm 6,93 c$ \\
\hline S3: SP2 & $<0,0001$ & $54,07 \pm 9,95^{\mathrm{a}}$ & $23,32 \pm 0,92^{\mathrm{b}}$ & $29 \pm 4,93^{b}$ \\
\hline S3: SP3 & $<0,0001$ & $38,4 \pm 2,38^{\mathrm{a}}$ & $35,07 \pm 0,33^{\mathrm{a}}$ & $35,33 \pm 1,76^{\mathrm{a}}$ \\
\hline
\end{tabular}

*Means assigned the same letter in the same column are not significantly different according to the T-multiple test at $\mathrm{P} \leq 0.001$

\subsubsection{Surfaces of Lesions Caused by Pathogenic Fungi on Cocoa Pods}

In plots of the cocoa system under the shade of fruit trees and forest species, brown pod rot caused by P. megakarya has developed lesion areas of about $40 \mathrm{~cm}^{2}$ during the dry season and about $220 \mathrm{~cm}^{2}$ during the rainy season. Black rot caused by $B$. theobromae has developed lesion areas of about $35 \mathrm{~cm}^{2}$ in the dry season and about $120 \mathrm{~cm}^{2}$ in the rainy season. Pod anthracnose caused by $C$. gloeocoporiodes has developed lesion areas of about $32 \mathrm{~cm} 2$ in the dry season and

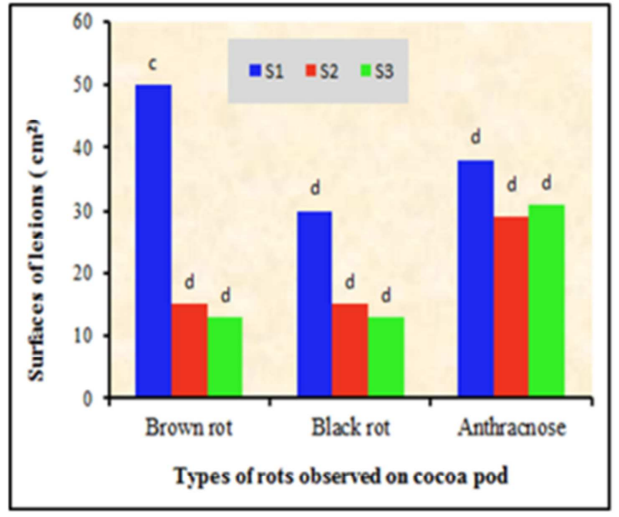

Dry season about $150 \mathrm{~cm}^{2}$ in the rainy season.

In the plots of the cocoa system associated with bananas and oil palms, the 3 types of rots presented lesion surfaces of less than $25 \mathrm{~cm}^{2}$ during the dry season and less than $120 \mathrm{~cm}^{2}$ during the rainy season.

In plots of the cocoa system associated with coffee trees, anthracnose developed lesion areas of about $40 \mathrm{~cm}^{2}$ during the dry season and about $180 \mathrm{~cm}^{2}$ during the rainy season. These lesions reflected a higher severity of anthracnose compared to brown rot and black rot.

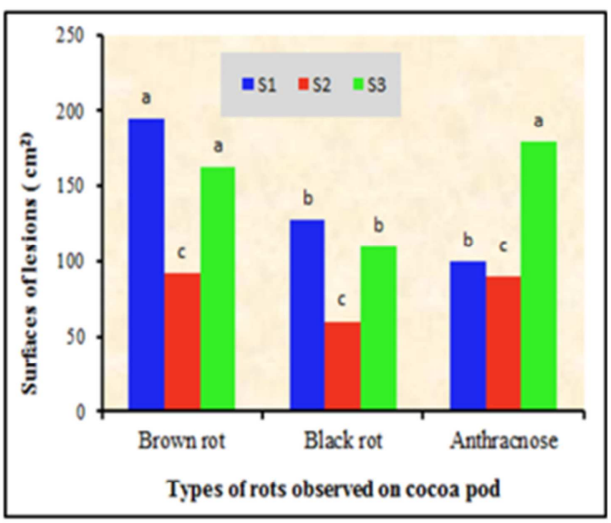

Rainy season

Figure 8. Evolution of lesion surfaces according to the types of rots observed, cocoa-based cropping systems and the seasons of the year. 
The comparison of the means of the evolution of surfaces of lesions by the T-multiple test showed that the interaction season of the year: cropping systems has a highly significant effect $(\mathrm{p}<0.01)$ on the evolution lesion surfaces.

Table 3. Comparison of means and standard deviations of lesion surfaces on pods by the T-multiple test according to the effect of cropping systems and seasons of the year.

\begin{tabular}{|c|c|c|c|c|}
\hline \multirow{2}{*}{ Treatments } & \multirow{2}{*}{ P-value } & \multicolumn{3}{|c|}{ Mean and standard deviation } \\
\hline & & Brown rot & Black rot & Anthracnose \\
\hline S1: SS1 & 0,0186607 & $50,3 \pm 20,85^{\mathrm{c}}$ & $25,00 \pm 7,51^{d}$ & $32,33 \pm 22,06 \mathrm{~d}$ \\
\hline $\mathrm{S} 1: \mathrm{SS} 2$ & 0,0188734 & $51,0 \pm 26,10^{c}$ & $29,3 \pm 6,96^{\mathrm{c}}$ & $25,66 \pm 29,78^{\mathrm{c}}$ \\
\hline S1: SS3 & 0,040554 & $15,33 \pm 8,68^{\mathrm{d}}$ & $14,33 \pm 10,01^{\mathrm{d}}$ & $20,43 \pm 0,66^{\mathrm{d}}$ \\
\hline S2: SS1 & 0,85951 & $16,3 \pm 22,67^{\mathrm{d}}$ & $15,33 \pm 26^{\mathrm{d}}$ & $22 \pm 35,82^{d}$ \\
\hline $\mathrm{S} 2: \mathrm{SS} 2$ & 0,9873 & $14,00 \pm 14^{\mathrm{d}}$ & $16,67 \pm 12,57^{d}$ & $23,60 \pm 13,83^{\mathrm{d}}$ \\
\hline $\mathrm{S} 2: \mathrm{SS} 3$ & 0,96829 & $16,67 \pm 10,72^{\mathrm{d}}$ & $16,00 \pm 22,52^{d}$ & $15,66 \pm 11,54^{\mathrm{d}}$ \\
\hline S3: SS1 & 0,0388173 & $35,7 \pm 41,01^{\mathrm{d}}$ & $28,67 \pm 11,28^{d}$ & $36,60 \pm 17,47^{d}$ \\
\hline S3: SS2 & 0,0047085 & $31,7 \pm 5,66^{d}$ & $27,0 \pm 6,66^{d}$ & $40,33 \pm 15,13^{d}$ \\
\hline S3: SS3 & 0,043418 & $29,7 \pm 26,59^{d}$ & $200,0 \pm 12^{\mathrm{d}}$ & $39,42 \pm 27,15^{\mathrm{d}}$ \\
\hline S1: SP1 & 0,0404959 & $233,0 \pm 17,78^{\mathrm{a}}$ & $105,3 \pm 14,52^{b}$ & $201,33 \pm 23,84^{\mathrm{a}}$ \\
\hline S1: SP2 & 0,0699416 & $214,7 \pm 16,66^{\mathrm{a}}$ & $106,7 \pm 6,11^{\mathrm{b}}$ & $208 \pm 9,68^{\mathrm{a}}$ \\
\hline S1: SP3 & 0,0242609 & $224,3 \pm 46,23^{d}$ & $84,33 \pm 15,02^{\mathrm{c}}$ & $122,66 \pm 8,41^{\mathrm{b}}$ \\
\hline S2: SP1 & 0,789771 & $56,7 \pm 40,08^{c}$ & $54,7 \pm 20,03^{\mathrm{c}}$ & $56 \pm 28,38^{c}$ \\
\hline $\mathrm{S} 2: \mathrm{SP} 2$ & 0,0464514 & $73,67 \pm 9,20^{c}$ & $65,00 \pm 7,33^{c}$ & $65,33 \pm 5,50^{c}$ \\
\hline S2: SP3 & 0,0473976 & $62,33 \pm 3,28^{c}$ & $63,67 \pm 25,45^{c}$ & $59,30 \pm 7,17^{c}$ \\
\hline S3: SP1 & 0,002128 & $152,7 \pm 9,26^{\mathrm{a}}$ & $93,00 \pm 49,26 c$ & $108,66 \pm 15,87 d$ \\
\hline S3: SP2 & 0,000037 & $109,3 \pm 12,34^{\mathrm{b}}$ & $165,3 \pm 26,43^{b}$ & $175,66 \pm 38,43^{\mathrm{a}}$ \\
\hline S3: SP3 & 0,000076 & $139,0 \pm 4^{b}$ & $135,0 \pm 22,33^{\mathrm{b}}$ & $120,66 \pm 31,74^{\mathrm{b}}$ \\
\hline
\end{tabular}

* Means assigned the same letter in the same column are not significantly different according to the T-multiple test at $\mathrm{P} \leq 0.000$

\subsection{Discussion}

\subsubsection{Prevalence of Fungi Responsible for Cocoa Bean Rots}

The variations observed in the development of fungi associated with cocoa pods revealed that the prevalence of fungal species depends on the seasons of the year, the relative humidity prevailing in the cocoa tree and the nature of the plants associated with the cocoa trees. These results corroborate those obtained by previous studies [1, 2], who explained that long-term changes in rainfall, relative humidity and temperatures have direct consequences on the aggressiveness of pathogens and insect pests cultures [9]. Phytophthora megakarya appeared to be the most aggressive fungus on cocoa pods associated with fruit trees Fusarium oxysporum was identified as the most frequent species on pods of cocoa trees associated with plantain and oil palm. Banana and oil palm are crops that are quite vulnerable to Fusarium wilt; the spores of $F$. oxysporum are generally disseminated in the plots by the action of strong winds in the equatorial zone. C. gloeosporioides has been isolated with a higher frequency from cocoa pods associated with coffee trees; this fungus has long been identified with $C$. kahawae as exerting a pathogenic action in the co-infection of coffee berries for the development of anthracnose. The prevalence of anthracnose on cocoa pods associated with coffee trees in the locality of Tonga can be explained by the association of the cocoa tree with the coffee tree. These results corroborate those obtained by previous studies [10,11, 14], who asserted that disease is quite common in a field when the previous crop and the combination crops are all susceptible.

\subsubsection{Rotate of Pods and Surfaces of Lesions Caused by Pathogenic Fungi}

All pods inoculated with isolates of $P$. megakarya, $B$. theobromae, and $C$. gloeocoporiodes developed rots compared to negative controls. These fungi are therefore responsible for rotting cocoa pods. These results are contrary to those obtained by previous studies [12], who observed that cocoa pod rots in Cameroon are caused by 8 strains of Phytophthora megakarya which can be collected in different cocoa production areas. The infection rates of brown rot, black rot, anthracnose as well as lesion areas on cocoa pods were highest during the rainy season i.e. from August to October. This result corroborates those obtained by previous studies [13], who showed that rain is a factor in the dispersion of the disease.

\section{Conclusion and Recommendations}

This study revealed a diversity of fungi constantly associated with cocoa pods in fields. However, it has been observed that pod rots in cocoa-based cropping systems are usually caused by Phytophthora megakarya, Botryodiplodia theobromae, and Colletotrichum gloeocoporiodes. These rots have a high incidence during the rainy season. In addition, the prevalence of fungi varies from one cocoa plantation to another depending not only on the seasons of the year, but also on the plant species associated with the cocoa trees.

Producers are therefore advised to considerably reduce the number of fruit trees and forest species which would promote the rise in relative humidity, which is a factor that favors the development of pathogenic fungi in cocoa pods. 


\section{Acknowledgements}

This work in plant pathology was carried out with the brilliant collaboration of all the staff in service at the Microbiology laboratory of the University of Yaoundé I.

\section{References}

[1] Mfegue V., Mbenoun M., Ten Hoopen M., Techou Z., Badjeck I., Ducamp M., and Ivors K., 2002. Development of a prophylactic control method against brown pod rot of cocoa, based on the participatory identification of primary foci of infection of the agent Phytophthora megakarya in the field. IRAD- Cameroon, Montpellier International Cooperation Center, Department of Plant Protection.

[2] Ndoumbè-Nkeng M., 2002. Incidence of agro-ecological factors on the epidemiology of brown rot in cocoa tree fruits in Cameroon: contribution to the establishment of an agricultural warning model. Doctoral thesis. National Agronomic Institute Paris-Grignon.

[3] Pohe J., Koula J., MIAN Jacques Dutron.., OKou Staella Florence. 2020. Spatio-temporal dynamics of the brown rot of cocoa pots due to phytophthora $s p$. in the department of Aboisso (Cote d'Ivoire) Journal of Applied Biosciences 145: 14842-14852.

[4] Klemmer H. W. and Lenney J. F. 1965. Lipids stimulating sexual reproduction and growthin Phytiaceous fungi. Phytopathology 55: 320-323.

[5] Zhu J., Zhang Z., Yang Z., 2001. General research methods on pathogen of potato late blight (Phytophthora infestans). Journal of Agricultural Sciences, 24: pp 112-114.

[6] Evans H. C., Holmes K. A. and Thomas S. E., 2003. Endophytes and mycoparasites associated with an indigenous forest tree, Theobroma gileri, in Ecuador and preliminary assessment of their potential as biocontrol agents of cocoa diseases. Mycological Progress 2: pp 149-160.
[7] Ribini M. R., Silva-Ribeiro R. T., 2005. Diversity of endophytic fungal community of cacao (Theobroma cacao L.) and control of Crinipellis perniciosa, causal agent of Witches 'Broom Disease. Int. J B Sci. 1: pp 24-33.

[8] Blaha G., 1989. Phytosanitary status of the Njolé cocoa plantation in Koulamoutou (Ogoué-solo province). Report of mission to Gabon with Socagab. p 68.

[9] Butt (T. M.), Hajek (A. E.) and (R. A.) Humber 1994: The effect of temperature on growth and survival of protoplasts of the gypsy moth pathogen Entomophaga maimaiga. J. Invertebr. Pathol., 64: 74-75.

[10] Champeil A., Fourbet J., Dore T., Rossignol L. 2004. Influence of cropping system on Fusarium head blight and mycotoxin levels in winter. Crop Protection, 23 (6), 531-537.

[11] Jagoret. P., 2011, thesis Analysis and evaluation of complex agroforestry systems over the long term: Application to cocoabased cropping systems in central Cameroon. Monpellier SupAgro.

[12] Mboussi S. B., Ambang Z., Ndogho A., Ngoh Dooh P. J., Essouma M. F., 2016. In-vitro Antifungal Potential of Aqueous Seeds extracts of Azadirachta indica and Thevetia peruviana against Phytophthora megakarya in Cameroon. Journal of Applied Life Sciences International 4 (4): pp 1-12.

[13] Deberdt P., Mfegue CV, Tondje PR, Bon MC, Ducamp M., Hurard C., Begounde BAD, Ndoumbe-Nkeng M., Hebbar PK, Cilas C., 2008. Impact of environmental factors, chemical fungicide and biological control on cocoa pod production dynamics and black pod disease (Phytophthora megakarya) in Cameroon. Biological Control 44: 149-159.

[14] Venance-Pacques Gniayou Kouadjo., BI Tra Aimé Vroh, Kouassi Bruno Kpangui, Affia Sonmia 2018. Effect of shade on phenotypic characters of cocoa tree in the forest-savannah transition zone in central Côte d'Ivoire. EDP Sciences 2018: pp 1-12. 